\title{
EŁONA CURKAN-DRÓŻKA
}

\author{
0000-0002-5256-433X \\ Uniwersytet Łódzki \\ Wydział Filologiczny \\ Instytut Rusycystyki \\ Zakład Przekładu i Dydaktyki \\ 90-236 Łódź \\ ul. Pomorska 171/173 \\ elona.curkan@uni.lodz.pl
}

\section{СРЕДСТВА НЕВЕРБАЛЬНОЙ КОММУНИКАЦИИ В ПОЭЗИИ СЕРГЕЯ ЕСЕНИНА И СПОСОБЫ ИХ ПЕРЕВОДА НА ПОЛЬСКИЙ ЯЗЫК}

\section{NON-VERBAL COMMUNICATION IN THE POETRY OF SERGEI YESENIN AND THE METHODS OF TRANSLATING IT INTO POLISH}

В статье представлены результаты исследования, касающегося роли средств невербальной коммуникации (жестов и мимики) в поэзии Сергея Есенина, а также способов их перевода на польский язык. Автор статьи акцентирует коммуникативный потенциал данных средств и разнообразие заложенной в них информации. Особое внимание обращено на проявление черт идиостиля Есенина (антропоморфизация природных образов), выраженных с помощью средств невербальной коммуникации. В работе представлен анализ избранных переводческих приемов, а также рассмотрено влияние на поэтический текст трансформаций, примененных в процессе трансляции.

Ключевые слова: перевод, невербальные средства коммуникации, переводческие трансформации.

The article presents the results of a study on the role of non-verbal communication (gestures and facial expressions) in the poetry of Sergei Yesenin, as well as on the methods of translating thereof into Polish. The author of the article emphasises the communicative potential of these means and the diversity of information transmitted that way. Particular attention is paid to how the features of Yesenin's individual writing style (such as anthropomorphisation of nature) are expressed with the use of non-verbal communication. The paper brings an analysis of selected translation techniques, as well as of the impact on the poetic text of the transformations applied in the translation process.

Keywords: translation, non-verbal communication, translation transformations. 
В настоящее время убеждать кого-либо в том, что невербальные средства общения играют значимую роль не только в речевом диалоге (tête-à-tête), но и в передаче сообщения с помощью разных каналов коммуникации не стоит.

Исследования структуры диалога и значения в нем невербальных знаков ${ }^{1}$ ушли далеко вперед, и продолжая стремительно развиваться, предоставляют новые открытия, касающиеся таких коммуникативных кодов, как кинесика (движения тела), вокалика (акустические особенности голоса), хаптика/такесика (осязание, касания), проксемика (расположение в пространстве), хрономика (оценка и распределение времени), ольфактика (запахи).

Однако при всем углубленном изучении данной сферы общения, довольно небольшое количество трудов посвящено значению и функционированию этих средств в области художественной литературы, и совсем небольшим количеством отмечены работы, посвященные наблюдениям за невербаликой при смене культурного кода, т. е. при переводе литературных произведений.

На недостаточную разработку таких работ обращает внимание польская ученая Люцилла Пшчоловска, которая отмечает, что в рамках поэтики роль средств невербальной коммуникации в литературном произведении установлена лишь частично, а, по мнению автора,

[...] powinny one stać się przedmiotem systematycznego badania na równi ze środkami języka, którym towarzyszą, które dopełniają, a czasem nawet zastępują. Tylko taka bowiem, wykorzystująca całe bogactwo elementów tekstowych, analiza pozwoli na pełny i adekwatny opis utworu literackiego ${ }^{2}$.

Из этого следует, что роль неречевых средств общения в литературном тексте неоспоримо велика и анализировать их функции и значение необходимо наравне с вербальными средствами, потому что лишь целостный анализ может предоставить нам полную и многостороннюю информацию, заложенную автором в текст.

Как было уже отмечено нами, разнообразие средств невербальной коммуникации чрезвычайно широко, к ним относятся жесты, мимика, продолжительность взгляда, тон, тембр голоса, скорость, паузы и интенсивность

${ }^{1}$ В 2000 г. было образовано Международное научное общество по изучению роли жестов в человеческом общении - International Society for Gesture Studies ISGS.

2 «[...] они должны стать предметом систематических исследований наравне со средствами языка, которым сопутствуют, которые дополняют, а порой даже заменяют. Только такой, использующий все богатство элементов текста анализ, позволит глубоко и адекватно описать литературное произведение» [везде в тексте перевод мой - Э. Ц-Д.]. См.: L. Pszczołowska, O zajwiskach parajęzyka w utworze literackim, «Pamiętnik Literacki» 1969, № 60/1, c. 147 . 
речи, использование интонаций, звуковые эффекты (смех, плач, вопль, покашливание и т. д.), физические особенности человеческого тела, касания и установление дистанции, выражение и оценка времени, артефакты, поэтому мы считаем необходимым в самом начале определить рамки нашего исследования. Мы сосредоточим свое внимание лишь на мимике и жестах, выступающих в поэзии Сергея Есенина, а также проследим трансформации, которые претерпевают данные средства выражения в процессе перевода. Прежде чем перейти к анализу переводов, мы попытаемся определить роль мимики и жестов ${ }^{3}$ в творчестве Есенина.

Учитывая, что при устном общении невербальные средства коммуникации несут на себе большую информационную нагрузку, стоит отметить, что в литературном произведении это соотношение выглядит немного иначе. С помощью языка тела (или благодаря ему) автор передает в основном значимую для данного произведения информацию, создает настроение, подчеркивает те моменты повествования или же состояния героя, на которых желает сфокусировать внимание читателя. Из этого следует, что язык телодвижений находится в неразрывной связи с происходящим, часто опережая вербальное сообщение или же существенно дополняя его.

Подобное замечает Сергей Пухачев в статье Жест и мимика y Ф. М. Достоевского ${ }^{4}$. По его мнению, с одной стороны, невербальные средства коммуникации литературных героев отличаются от реальной коммуникации, потому что автор передает их не комплексно, а скорее фиксирует выборочно, но, с другой стороны, то невербальное поведение, которое попадает в «поле зрения» читателя, несет в себе более «весомый» коммуникативный заряд и более значимые черты психологической характеристики героя.

По отношению к поэзии необходимо подчеркнуть, что в ней иначе, чем в прозе, передается несловесное поведение героев. Полный описательный характер данных средств часто невозможен в связи с формой произведения, поэтому невербальные средства коммуникации представлены сжато, но предельно содержательно. Принимая роль важных штрихов, они удерживают на себе внимание реципиента, тем самым передавая имплицитную информацию, которая при внимательном и вдумчивом прочтении, в силах «сказать» нам даже больше, чем вербальные носители. Как утверждает Ольга Клаутова, например, жест «[...] это та семантическая единица, тот ключ,

\footnotetext{
${ }^{3}$ Среди всех средств невербальной коммуникации больше всего места в научных исследованиях уделяется именно жестам. См.: А. Załazińska, Niewerbalna struktura dialogu, Kraków: Universitas 2006, c. 73.

${ }^{4}$ С. Пухачев, Кинеситические наблюдения над романом Ф. М. Достоевского «Преступление и наказание», «Вестник Новгородского государственного университета» 2006, № 36, с. 47.
} 
который позволяет открыть дверь в эмоциональный мир не только человека, но и всего произведения в целом» ${ }^{5}$.

В ходе анализа нами было отмечено, что мимика и жесты (со значительным преобладанием жестов) в произведениях Есенина присущи не только человеческим героям, но и в связи со спецификой идиостиля поэта - мы имеем в виду развернутую и многослойную метафоричность природных образов - они являются важной составляющей тех метафор, в которых «действующим лицом» является именно природа. С помощью невербального поведения автор создает очень достоверные «человеческие» образы, происходящие из природы. Причем жесты и мимика, применяемые поэтом при олицетворении, передают целый спектр поведения «природных героев» - физические качества, эмоциональное состояние, богатый духовный мир, участие в повседневной жизни. Перенос человеческих жестов и мимики на явления природы, флору и фауну подчеркивает слияние этих двух миров, согласно мировидению поэта, проявляющемуся в его поэзии как своеобразный лейтмотив.

Мы проиллюстрируем вышесказанное несколькими примерами ${ }^{6}$ : «Седые вербы у плетня / Нежнее головы наклонят» («Устал я жить в родном краю...», с. 32), «Под окном от скользких елей / Тень протягивает руки» («О товарищах веселых...», с. 46), «Рассвет рукой прохлады росной / Сшибает яблоки зари» («Пойду в скуфье смиренным иноком...», с. 12), «И горстью смуглою листвы последний ворох / Кидает ветер вслед из подола» (Голубень, с. 42), «И лишь волна потянется к звезде, / Мелькают мухи пеплом по воде» (Табун, с. 38), «Как будто бы на корточки погреться / Присел наш клен перед костром зари» (Исповедь хулигана, с. 124), «Вечер черные брови насопил» («Вечер черные брови насопил...», с. 142).

В поэзии Есенина, благодаря жестам и мимике, оживают и олицетворяются не только природные явления, но и культурные артефакты, например: «Водит старая мельница ухом, / Навострив мукомольный нюх» (Сорокоуст, с. 116), «Низкий дом без меня ссутулился» (Москва Кабаикая, с. 132).

Жесты и мимика часто являются «говорящей» составляющей метафорического образа, они подчеркивают отсутствие границ между человеческим и природным мирами также в сфере религии, например: «И на известку колоколен / Невольно креститься рука» (Запели тесанные дроги, с. 440), «Схимник ветер шагом осторожным / Мнет листву по выступам дорожным /

${ }^{5}$ О. Клаутова, Жест в древнерусской литературе и иконописи XI-ХІІІ вв. К постановке вопроса, [в:] Труды Отдела древнерусской литературы, ред. О. Белоброва, Д. Лихачев, Санкт-Петербург: РАН, «Дмитрий Буланин» 1993, т. XLVI, с. 257.

${ }^{6}$ Все фрагменты стихотворений, приведенные в статье, взяты из двуязычного сборника: S. Jesienin, Poezje, Стихотворения, выбрал Z. Fedecki, Kraków: Wydawnictwo Literackie Kraków 1975, изд. 1. 
И целует на рябиновом кусту / Язвы красные незримому Христу» (Осень, c. 56), «А степь под пологом зеленым / Кадит черемуховый дым» («За темной прядью перелесиц...», с. 48), «Крутит вихорь леса во все стороны, / Машет саваном пена с озер» (Русь, с. 22).

В некоторых случаях, используемые автором жесты, приковывая к себе внимание реципиента, становятся частью пугающей картины:

Слышите ль? Слышите звонкий стук?

Это грабли зари по пущам.

Веслами отрубленных рук

Вы гребетесь в страну грядущего

(Кобыльи корабли, с. 110).

Оттого в сентябрьскую склень

На сухой и холодный суглинок,

Головой размозжась о плетень

Облилась кровью ягод рябина

(Сорокоуст, с. 120).

После прочтения приведенных строк, по нашему мнению, действительно сложно определить о каком герое идет речь в произведении - о человеческом или о природном. Невозможность данного разграничения является результатом точного воспроизведения/отражения именно «человеческого» невербального поведения природными героями.

Анализ стихотворений Есенина, проведенный нами для данной статьи, показал, что мимические выражения в произведениях поэта встречаются намного реже, чем жесты, но тем не менее их роль часто является значительной в передаче эмоционального заряда стихотворения. Наиболее часто изменения мимики касаются взгляда (продолжительность, эмоциональная выразительность) и губ, и в большинстве случаев относятся к людям.

Проиллюстрируем это несколькими примерами:

Все они убийцы или воры

Как судил им рок

Полюбил я грустные их взоры

С впадинами щек.

Много зла от радости в убийцах.

Их сердца просты.

Но кривятся в почернелых лица

Голубые рты.

[...]

И когда с улыбкой мимоходом

Распрямлю я грудь,

Языком залижет непогода,

Прожитой мой путь

(«В том краю, где желтая крапива...», с. 112). 
«Я улыбаюсь пашням и лесам, / А дед с тоской глядит на колокольню» (Возвращение на Родину, с.162), «Чем мать и дед грустней и безнадежней, / Тем веселей сестры смеется рот» (Возвращение на Родину, с.164), «Мир осинам, что, раскинув ветви / Загляделись в розовую водь» («Мы теперь уходим понемногу...», с. 168).

При переводе художественных произведений в целом, и поэзии в частности, необходимо отметить, что большое значение имеет вдумчивое прочтение произведения, а также его предпереводческий анализ, который поможет переводчику сосредоточить внимание на тех сложных аспектах текста, которые потребуют особой бдительности в процессе перевода. При работе над поэтическим произведением необходимо также учесть дополнительные трудности, такие как: попытка воссоздать рифму, ритм и размер произведения, но тем не менее при сохранении данных «атрибутов поэзии», стоит придерживаться внутренних установок, которые будут удерживать перевод в определенной близости к оригиналу, и помогут избежать значительных искажений.

Приняв во внимание, что невербальные средства коммуникации в плане значимости передаваемой ими семантики «не уступают» вербальным, то в переводе им должно уделяться не меньшее внимание, что отмечают и сами переводчики. Итак, например, Шон Годлен, анализируя перевод стихотворения Катулла, выполненный Луисом Зукофским, делает существенное для нас замечание: «For Zukofsky it was clear that these physical actions were formal elements of the original poem that should be respected in the translation» ${ }^{7}$.

Обратимся к анализу польских переводов стихотворений Есенина и проследим переводческие приемы и трансформации, которые произошли в процессе перекодирования.

Одним из частых, отмеченных нами, приемов является перевод жеста/ мимики с помощью его замены на похожий жест или посредством добавления к жесту уточняющей детали, например:

Но вот приподнял брови,

Протер рукой глаза,

Вбежал обратно в хату

И стал под образа

(Товарищ, с. 78).

Lecz nagle uniósł głowę

Twarz obtarł załzawioną

\footnotetext{
${ }^{7}$ S. Golden, "Whose morsel of lips will you bite?" Some reflections on the role of prosody and genre as non-verbal elements in the translation of poetry, [в:] Nonverbal Communication and Translation, ред. F. Poyatos, Amsterdam: John Benjamins Company 1997, с. 228. Для Зукофского было совершенно очевидным, что физическое поведение являлось формальным элементом в оригинальном произведении, и необходимо уделить ему должное внимание в переводе.
} 
Na powrót wbiegł do izby

I stanął pod ikoną

(Towarzysz, c. 79, перевел Т. Монгирд).

Приподнять брови и приподнять голову - как мимическое движение, так и жест, несмотря на широкий спектр толкований, могут быть проявлены в ситуации, когда мы пытаемся что-либо вспомнить, либо нас осеняет новая идея. В данном случае - жест и мимика выражают, что должно быть герою в голову пришло новое (возможно неожиданное) решение, замена мимики близким по значению жестом, по нашему мнению, не повлекла за собой изменений в передаче информации, не изменила также прагматический заряд произведения, лишь в незначительной степени повысив динамику поведения героя.

Рассмотрим следующие примеры:

«Приметный клен уж под окном не машет»

(Возвращение на Родину, с. 160).

«Znajomy klon nie macha już konarem»

(Powrót do ojczyzny, перевел Я. Бжехва, с. 161).

- в данном случае переводчик, вводя дополнительную информацию, (в переводе клен не просто машет, а машет именно ветвями) в определенной степени сглаживает метафоричность данного образа. Напомним, что у Есенина нет четкого разграничения природного и человеческого поведения - растения, явления природы, животные - функционируют, чувствуют и обладают всеми физическими качествами, которые соответствуют людям. Необходимо также отметить, что в лирике Есенина клен наделен особой символикой - его образ, переходя из стихотворения в стихотворение, претерпевает изменения - это дерево проживает все стадии человеческого существования, оно растет, развивается и стареет вместе с лирическим героем. Приняв эту особенность во внимание, можно предположить, что поэт, не без основания, не уточняет, чем именно машет клен, соединяя в метафоре образ дерева с человеческим другом, в связи с этим дополнение «машет ветвями», стирая олицетворение, в определенной степени искажает значение авторского образа.

Следующий фрагмент стихотворения представляет обратный эффект данного приема - изменение образа при отсутствии в переводе детали, дополняющей жест.

«Сядь ко мне на крылечко / Тихо склонись ко плечу»

(Иорданская голубииа, с. 100). 
«Obok mnie, siądź na ganeczku, / Siądź z pochyloną głową»

(Gołąbka Jordanu, перевела М. Бучкувна, с. 101).

Отсутствие в переводе направления движения головы (в оригинале голова склоняется к плечу, в переводе просто склоняется) - существенно изменяет прочтение данного жеста, так как просто склонить голову, согласно Словарю языка русских жестов ${ }^{8}$, означает выразить смирение, скорбь (в данном случае более подходящим истолкованием является выразить смирение), то же самое толкование жеста существует и в польской культуре. Однако обратим внимание на то, что в стихотворении Есенина наклонение головы происходит с целью опереть ее о чье-то плечо, что существенно меняет его семантику - положить голову кому-то на плечо, значит довериться данному человеку, искать опору в нем, оказывать нежные чувства, что соответствовало бы изображенной автором картине (мужчина просит сесть рядом женщину и предлагает ей опереть свою голову о его плечо). Эти коннотации исчезают из текста перевода, изменяя характер представленной картины - в польском варианте мужчина предлагает сесть рядом женщине с опущенной головой. Нехватка элемента «склониться к плечу» приводит к иному пониманию жеста и нивелирует в созданном образе нежные чувства героев друг к другу.

В ходе анализа мы обратили внимание на еще один прием, который также применялся переводчиками, а именно на замену жестов и мимики в переводе - жестами и мимикой с расхожим значением. Приведем несколько примеров:

«Мир осинам, что, раскинув ветви / Загляделись в розовую водь» («Мы теперь уходим понемногу...», с. 168).

«Pokój wam, osiki, co szepczecie / Liść rozplótłszy nad odbiciem swoim» («Odchodzimy sobie powolutku...», перевела А. Каменьска, с. 169).

В оригинале деревья, разложив в стороны ветви, всматриваются в свое отражение в воде - эта картина передает часто встречающийся, родной сердцу поэта пейзаж. В произведении не появляется звук, природа созерцает мир в тишине, также, как и лирический герой - их настроения схожи (этот «эмоциональный параллелизм» часто применяется Есениным). В переводе же деревья не соблюдают тишину - они шепчутся над своим отражением, вызывая тем самым ассоциацию с девушками, которые всматриваются в зеркало воды (данные ассоциации усиливает начало второй строки - «liść rozplótłszy», т. е. расплетая листья косы). Из перевода исчезает чувство совместного созерцания происходящего, прощания с миром.

${ }^{8}$ Словарь языка русских жестов, сост. С. А. Григорьева, Н. В. Григорьев, Г. Е. Крейдлин, Москва-Вена: Языки русской культуры 2001, с. 130-131. 
Следующий перевод обратит наше внимание на сглаживание черт есенинского мировосприятия, в котором ярко выражалась любовь к животным, такая же сильная и искренняя, как и к людям. Автор неоднократно подчеркивает в своей поэзии, что их доверие и дружбу он ценит порой даже больше, чем человеческие.

\author{
Он пришел целовать коров, \\ Слушать сердцем овсяный хруст \\ Глубже, глубже серпы стихов! \\ Сыпь черемухой, солнце - куст! \\ (Кобыльи корабли, с. 114). \\ Przyszedł krowy gładzić po sierści \\ Słuchać sercem jak trzeszczy owies. \\ Głębiej, głębiej, sierpy moich wierszy! \\ Syp czeremchą, słoneczne pąkowie! \\ (Kobyle okręty, перевел Е. Енджеевич, с. 115).
}

У Есенина лирический герой для того, чтобы выразить свои чувства к братьям нашим меньшим не использует жест поглаживания, а целует их, т. е. выражает свои чувства так же, как и по отношению к людям. Данный жест далеко не случаен - поглаживание животного, являясь привычным жестом, не удивляет реципиента, а вот дружеский поцелуй акцентирует особенность чувства, которое герой испытывает к животному. Замена жеста, по нашему мнению, в данном случае затушевывает важную черту авторского мировосприятия.

Мы хотели бы обратиться к еще одному, интересному для нашего исследования, примеру9 ${ }^{9}$ замены мимики жестом:

Вечер черные брови насопил.

Чьи-то кони стоят у двора.

Не вчера ли я молодость пропил?

Разлюбил ли тебя не вчера?

(«Вечер черные брови насопил...», с. 142).

Koń u przyzby grzebie kopytem.

Wiatr odrzuca kosmyki z czoła.

Młode dni moje - już przepite?

Miłość moja - i ta skończona?

(«Koń u przyzby grzebie kopytem...», перевел В. Ворошильски, с. 143).

${ }^{9}$ Данный пример был в более широком плане рассмотрен нами в монографии: E. Curkan-Dróżka, Метафора в творчестве Сергея Есенина и ее перевод на польский язык, Łódź: Wydawnictwo Uniwersytetu Łódzkiego 2018, c. 111-112. 
Итак, несложно заметить, что в данном произведении «выражение лица» ветра, выступающее в первой строке, несет в себе сильнейший эмоциональный заряд - не будет преувеличением отметить, что по нему одному можно точно угадать настроение предстоящего повествования.

В переводе Виктора Ворошильского мимика ветра полностью трансформируется. Подлинный «вечер» заменен здесь «ветром», однако, внимание читателя сосредотачивается не на самом «субъекте», а на изменении выражения его лица (в переводе жеста), которое наделено глубоким смыслом. «Вечер насопил брови» - значит разгневался, нахмурился, выражает неодобрение, задумался о чем-то нелегком. В этом образе заключен смысловой заряд всего произведения, в котором лирический герой отдает себе отчет в том, что молодость уже безвозвратно ушла. И это горькое ощущение разделяет с ним окружающая природа. У Ворошильского, несмотря на то, что олицетворение природного явления не, стирается - трансформация мимики в жест значительно изменяет картину происходящего и «направляет эмоции» по совершенно другому курсу. В переводе ветер убирает со лба пряди волос - этот «игривый» жест никак не помещается в общую картину, которая насыщена такими чувствами как подавленность, потеря. Он прерывает ассоциативную цепочку, искусно созданную автором, и приводит к расхождению настроения произведения и переданной с помощью невербалики информации.

Приближаясь к завершению нашего исследования, мы считаем необходимым представить прием введения жеста в переводе в том месте, где он отсутствовал в оригинале ${ }^{10}$. В стихотворении «Запели тесанные дроги...» мы наблюдаем следующую картину:

И не отдам я эти цепи,

И не расстанусь с долгим сном,

Когда звенят родные степи

Молитвословным ковылем (с. 83)

- автор представляет образ, основанный на зрительных и слуховых коннотациях - ковыль, пригибающийся к земле, ассоциируется поэту с молящимися прихожанами. Однако данное сходство выражено не жестом, а эпитетом «молитвословный». В переводе, выполненным Тадеушем Монгирдом:

Nie targnę się na te okowy

I sen śnić będę nieprzespany.

Gdy w moim stepie szafirowym

\footnotetext{
${ }^{10}$ Более подробно об этом см.: E. Curkan-Dróżka, Mетафора в творчестве Сергея Есенина ..., с. 139-140.
} 
Na klęczkach modlą się burzany

(«Śpiewają osie jaworowe...», перевел Т. Монгирд, с. 45)

- мы наблюдаем следующие изменения, а именно эпитет «молитвословный» переводчик воспроизводит с помощью непосредственного жеста, изображающего моление, во время которого верующие находятся в согнутой позиции - на коленях. Данную ассоциацию в построении схожего образа мастерски использовал Монгирд, в польском варианте мы наблюдаем за тем, как «na klęczkach modlą się burzany», т. е. бурьян молится на коленях. Благодаря введению адекватного жеста переводчику удалось не только сохранить метафору, полностью отвечающую есенинской поэтике, но и передать ту же информацию, не изменяя ассоциаций.

Подводя итог нашего исследования отметим, что в большинстве случаев рассматриваемые нами невербальные средства коммуникации были замечены переводчиками. Однако не все переводческие приемы способствовали их адекватному отражению в польском варианте стихотворений.

Трансформация жестов и мимики наиболее часто приводила к нивелированию мировоззренческих установок поэта, ярко выраженных в его произведениях, оказывала значительное воздействие на смену эмоциональной окраски, либо переиначивала созданный автором образ. Данные модификации, введенные в перевод, привели к изменению прагматического пласта произведения и к снижению силы экспрессии.

Обратим внимание, что в исследуемых нами примерах нередкими были случаи, когда именно в жестах и мимике был заложен ключ, который при внимательном прочтении мог привести реципиента к глубокому и целостному восприятию стихотворения. Несомненно, средства невербальной коммуникации добавляют важные штрихи в общую картину, которую рисует наше воображение при рецепции поэзии. Процесс расшифровки невербальных знаков, а затем их адекватной передачи является задачей сложной, требующей от переводчика высокого уровня чувствительности и внимательности к многоуровневой структуре произведения.

\section{References}

Curkan-Dróżka, Ełona. Metafora v tvorchestve Sergeya Esenina i ee perevod na polskii yazyk, Łódź: Wydawnictwo Uniwersytetu Łódzkiego, 2018.

Golden, Sean. "Whose morsel of lips will you bite?" Some reflections on the role of prosody and genre as non-verbal elements in the translation of poetry. In: Nonverbal Communication and Translation, ed. F. Poyatos, Amsterdam: John Benjamins Company, 1997.

Jesienin, Sergiusz. Poezje. Kraków: Wydawnictwo Literackie, 1977. 
Klautova, Olga. Zhest v drevnerusskoi literature i ikonopisi XI-XIII vv. K postanovke voprosa. In: Trudy Otdela drevnerusskoi literatury, ed. O. Belobrova, D. Likhachev. Vol. XLVI. SanktPeterburg: RAN, "Dmitrii Bulanin", 1993: 257-263.

Pszczołowska, Lucylla. "O zjawiskach parajęzyka w utworze literackim”. Pamiętnik Literacki, No. 60/1 (1969): 139-147.

Pukhachev, Sergei. "Kinesiticheskie nablyudeniya nad romanom F. M. Dostoevskogo 'Prestuplenie i nakazanie"”. Vestnik Novgorodskogo gosudarstvennogo universiteta, No. 36 (2006): 46-49.

Slovar yazyka russkikh zhestov, sost. S. A. Grigorieva, N. V. Grigoriev, G. E. Kreidlin. MoskvaVena: Yazyki russkoi kultury, 2001.

Załazińska, Anna. Niewerbalna struktura dialogu. Kraków: Universitas, 2006. 